\title{
50 Anos da Faculdade de Medicina de Ribeirão Preto-USP: Mudanças nas Atividades Meio
}

\author{
Helena L. Alves de Lima Furtado'; Alcione Flávia de Castro; \\ Ivana Geraldo Cintra Faria ${ }^{3}$ \& Regina Célia da Rocha Bezerra ${ }^{4}$ \\ ${ }^{1}$ Assessora de Planejamento e Gestão. ${ }^{2}$ Assistente Técnico Administrativo. ${ }^{3}$ Assistente Técnico Acadêmico. \\ ${ }^{4}$ Assistente Técnico Financeiro. Faculdade de Medicina de Ribeirão Preto - USP.
}

A s atividades de apoio administrativo* ao ensino, pesquisa e extensão de serviços da Faculdade de Medicina de Ribeirão Preto da Universidade de São Paulo (FMRPUSP), desde sua criação, têm passado, alternadamente, por períodos de adaptação e de desenvolvimento. Esses movimentos periódicos, parecem depender de muitas variáveis, dentre as quais destacam-se os avanços tecnológicos, principalmente, dos equipamentos e programas de informática, e os progressos científicos da academia, nas atividades de ensino, pesquisa e extensão de serviços.

Subjacente a aparente simplicidade, encontrase a influência de múltiplas variáveis, na evolução das atividades de apoio às atividades-fim: a história da FMRP-USP, as peculiaridades regionais, a cultura organizacional, percebida nas marcas deixadas pelos fundadores e os valores e normas instituídos. Além de tais fatores, que imprimem a identidade da Instituição, estão as políticas de Estado, presentes nas políticas de recursos humanos e no próprio processo de trabalho, comuns a todas as Unidades de Ensino** da USP. $\mathrm{O}$ estudo das políticas mostra a forma como a Instituição mantém os seus funcionários e os direciona para a realização dos objetivos institucionais, no contexto social e político que se insere ${ }^{(1)}$.

Acrescenta-se aos fatores já mencionados a importância das lideranças eleitas, representantes dos anseios da comunidade e dos recursos humanos de apoio administrativo que, na dependência do grau de envolvimento com a profissão e com a organização, também podem influenciar mudanças. Segundo Schein $(1992)^{(2)}$, liderança e cultura são faces de uma mesma moeda.

As situações de mudança na gestão, aparentemente suaves, podem provocar turbulências internas importantes na administração dos recursos humanos. As mudanças organizacionais mobilizam os profissionais, por sinalizarem que o processo de trabalho, até então em vigência, já não atende às novas necessidades de apoio, pela evidência de disfunções. Entretanto, na dependência da flexibilidade e motivação dos profissionais, podem propiciar melhorias e mostrar as tendências futuras da Instituição.

A partir dos comentários feitos, colocam-se em relevo alguns momentos de mudança nas áreas de apoio acadêmico, administrativo, financeiro e de gestão, que correspondem aos progressos na administração da qualidade da FMRP-USP.

\section{A ÁREA ACADÊMiCA EM MOMENTO DE EXPANSÃO}

A Universidade de São Paulo vive um novo momento de expansão. Dentro desse espírito de ampliação de vagas e crescimento do ensino de graduação, a FMRP-USP reuniu esforços do corpo docente, técnico e administrativo na elaboração de propostas

*As atividades administrativas de apoio correspondem às atividades que dão suporte às atividades-fim das Unidades de Ensino da USP.
** Por Unidades de Ensino entende-se o conjunto das escolas, institutos e faculdades de ensino, pesquisa e extensão de serviços. 
de criação de novos cursos de graduação, que foram submetidos a apreciação e aprovados pelos órgãos colegiados da Universidade de São Paulo. A Assistência Técnica Acadêmica tem participado ativamente dos processos de discussão da academia, procurando atender os anseios dessa comunidade.

O aprimoramento permanente do ensino de graduação tem sido objeto de constantes debates nesta faculdade. A partir de 1998, iniciaram-se novas discussões sobre o aprimoramento do internato. Em 2002, ocorreu a revisão do Ciclo Básico do Curso de Ciências Médicas, concluindo-se um projeto de reestruturação, que está em fase de implantação.

Assim, a FMRP-USP atingiu grande expansão, atendendo à necessidade de ampliação de vagas em universidades públicas, e inserindo-se na "moderna concepção da atuação em saúde por meio de equipes multiprofissionais"(3). Em 2002, novas turmas iniciaram a graduação em Fisioterapia e Terapia Ocupacional e, em 2003, nova turma começará a graduação em Fonoaudiologia, Nutrição e Metabolismo e Informática Biomédica, em conjunto com a Faculdade de Filosofia, Ciências e Letras de Ribeirão Preto-USP.

Essa expansão traz à faculdade um novo momento acadêmico, administrativo e financeiro. Novamente o espaço público é preenchido com a excelência do ensino e da pesquisa, que são características intrínsecas da USP.

A aprovação dos novos cursos trouxe 39 novos claros docentes e, acrescentada às outras vias de reposição, houve um total de 71 novos docentes, que correspondem a um acréscimo de $29 \%$ do corpo docente em 4 anos. Os novos cursos, trouxeram, também, 20 claros de pessoal técnico e de recursos financeiros.

A FMRP-USP, ao longo dos seus 50 anos, tem demonstrado um alto grau de maturidade e competência. Atualmente, além da ampliação de vagas da graduação, chamamos a atenção para a constante preocupação com o aprimoramento do ensino de graduação. $\mathrm{O}$ contínuo apoio às atividades científicas pode ser exemplificado pela criação de uma secretaria específica para a Comissão de Pesquisa e o acolhimento pela FMRP-USP do SIICUSP (Simpósio Internacional de Iniciação Científica da Universidade de São Paulo). A forte vocação científica pode ser comprovada pela produção científica nacional e internacional da FMRP-USP, na área biomédica, no País. Um novo processo de coleta de dados da produção científica foi implantado.

Nos últimos anos, a área acadêmica tem vivido momentos de grandes mudanças e adaptações frente à nova fase vivida pela Instituição. Tem-se procurado aprimorar, continuadamente, a prestação dos serviços em busca da excelência do atendimento.

\section{EVOLUÇÃO DA ESTRUTURA ADMINIS- TRATIVA}

Os momentos mais importantes das modificações e desenvolvimento nas atividades desempenhadas pelo pessoal de apoio se mostram graficamente, quando a estrutura administrativa, representante simbólico da cultura organizacional, as apresenta por meio de mudanças significativas.

Os grandes períodos de permanência dessa estrutura administrativa sinalizam ainda que a organização adotada pode ser a que mais se adapta aos propósitos do apoio às atividades-fim da FMRP-USP.

Desde a fundação até 1984, o organograma, representação gráfica da estrutura administrativa da FMRP-USP (Figura 1), foi muito simples. Compunhase de uma Secretaria, uma Seção de Atividades Escolares e um Setor de Expediente. Na época, um mesmo funcionário desempenhava várias funções. De maneira geral, os funcionários dedicavam-se profundamente ao projeto de construção da faculdade, pelo reconhecimento da importância da instituição nascente. O ambiente de colaboração garantiu a instalação da Faculdade de Medicina de Ribeirão Preto e influenciou aqueles que, de alguma forma, participaram desse período e que, hoje, mantêm altas expectativas em relação aos profissionais de apoio.

Em 1984, 32 anos após a fundação da FMRPUSP, houve uma evolução significativa na estrutura administrativa da Unidade (Figura 2). Foram criadas duas Assistências Técnicas: Assistência Técnica Acadêmica (ATAC), com 4 Seções: Graduação, Pós-Graduação, Documentação Científica e Atividades Acadêmicas Gerais, além de 9 Setores, e a Assistência Técnica Administrativa (ATAD), com 3 Seções: Comunicações, Serviços Gerais, e Controle Financeiro além de 7 setores. que foram extintos em 1993.

Em 1995, foi criada a Seção Técnica de Informática, vinculada à Diretoria.

Em 1996, a Assistência Técnica Administrativa (ATAD), que incorporava as atividades financeiras, foi desmembrada, criando-se a Assistência Técnica Financeira(ATF) (Figura 3). No âmbito da ATAD, ficaram a Seção de Comunicações, a Seção de Pessoal, a Seção de Serviços Gerais e a Seção de Documentação Científica. No âmbito da ATF, ficaram a Seção de Contabilidade, a Seção de Controle Finan- 


\section{ORGANOGRAMA ADMINISTRATIVO DA FMRP - USP}

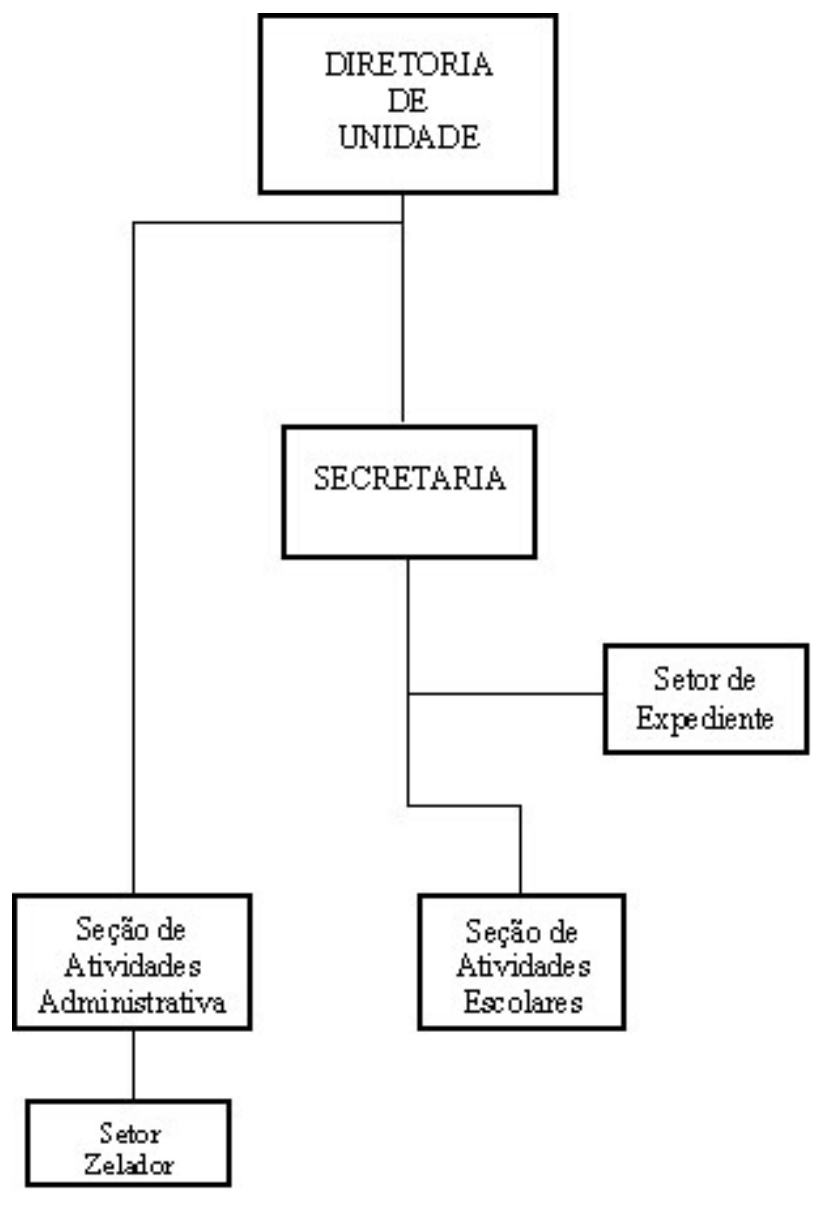

Figura 1 - Organograma Administrativo da FMRP-USP (1952-1984)

ceiro, criando-se uma Diretoria Técnica de Serviço para a gerência das atividades de compras nacionais e de importação.

Nesse processo evolutivo, destacamos o importante trabalho da Comissão Assessora de Recursos Humanos do CTA que, assessorada pela Assistência Técnica Administrativa, tem priorizado a capacitação pessoal, através de treinamentos, visando à aquisição de habilidades, conceitos e regras, que proporcionem uma melhoria do quadro funcional frente as exigências da Universidade.

Citamos, também, o novo modelo de recrutamento e seleção, implantado no final de 2001, que, dentro de critérios éticos, tem permitido selecionar candidatos adequados através de um processo isento e inovador.

\section{A ÁREA FINANCEIRA EM AMBIENTE DE MUDANÇAS}

A Universidade de São Paulo, apesar da sua autonomia***; tem recebido o impacto das políticas do Estado, através da legislação, principalmente em relação ao sistema financeiro. Em decorrência, é um sistema que tem sido modificado com grande freqüência.

Em 1996, foi criada a Comissão para a Reestruturação dos Sistemas de Gestão Financeira e de Materiais da USP, GEFIN, por meio da Portaria CODAGE****, de 26/07/1996. O GEFIN, constituído de funcionários de diversas unidades, tem a missão de "Buscar a excelência na gestão das áreas de finanças e de materiais da Universidade de São Paulo, com a participação ativa de todas as pessoas que atuam nessas áreas". A Comissão tem o objetivo de reavaliar as normas e procedimentos da USP, relacionados à administração de materiais e finanças, visando à modernização e à eficiência nos processos de suporte à tomada de decisão.

$\mathrm{O}$ acesso às informações da área pode ser obtido por meio da página http://www.recad.usp.gefim/

A partir de tais esforços e do aprimoramento contínuo dos procedimentos tem sido possível contar com instruções consolidadas, que oferecem respostas rápidas e seguras aos administradores. Esse apoio é muito necessário em razão da complexidade inerente aos atos da administração pública financeira, para assegurar o atendimento ao interesse público e para adaptar-se às constantes alterações na legislação e nas normas da USP.

Internamente, destaca-se a Comissão de Orçamento, Assessora da Diretoria da FMRP-USP para Assuntos do Orçamento, criada em 1981. Essa comissão teve importante papel, porque proporcionou maior visibilidade à aplicação dos recursos do orçamento da faculdade. Naquele ano, a comissão implantou um sistema sem precedente na unidade e, possivelmente, na USP, para a distribuição de parte do total dos recursos orçamentários da faculdade aos departamentos, com base em critérios amplamente debatidos na época e periodicamente nos anos seguintes, e que estão em vigor. Os critérios consideram os

\footnotetext{
${ }^{* * *}$ Conforme artigo $1^{\circ}$ do Estatuto de1988, "A Universidade de São Paulo, criada pelo Decreto 6.283, de 25 de janeiro de 1934 , é autarquia de regime especial, com autonomia didático-científica, administrativa, disciplinar e de gestão financeira e patrimonial".

**** Coordenadoria de Administração Geral da Universidade de São Paulo.
} 


\section{ORGANOGRAMAADMINISTRATIVO DA FACULDADE DE MEDICINA DE RIBEIRÃO PRETO-USP}

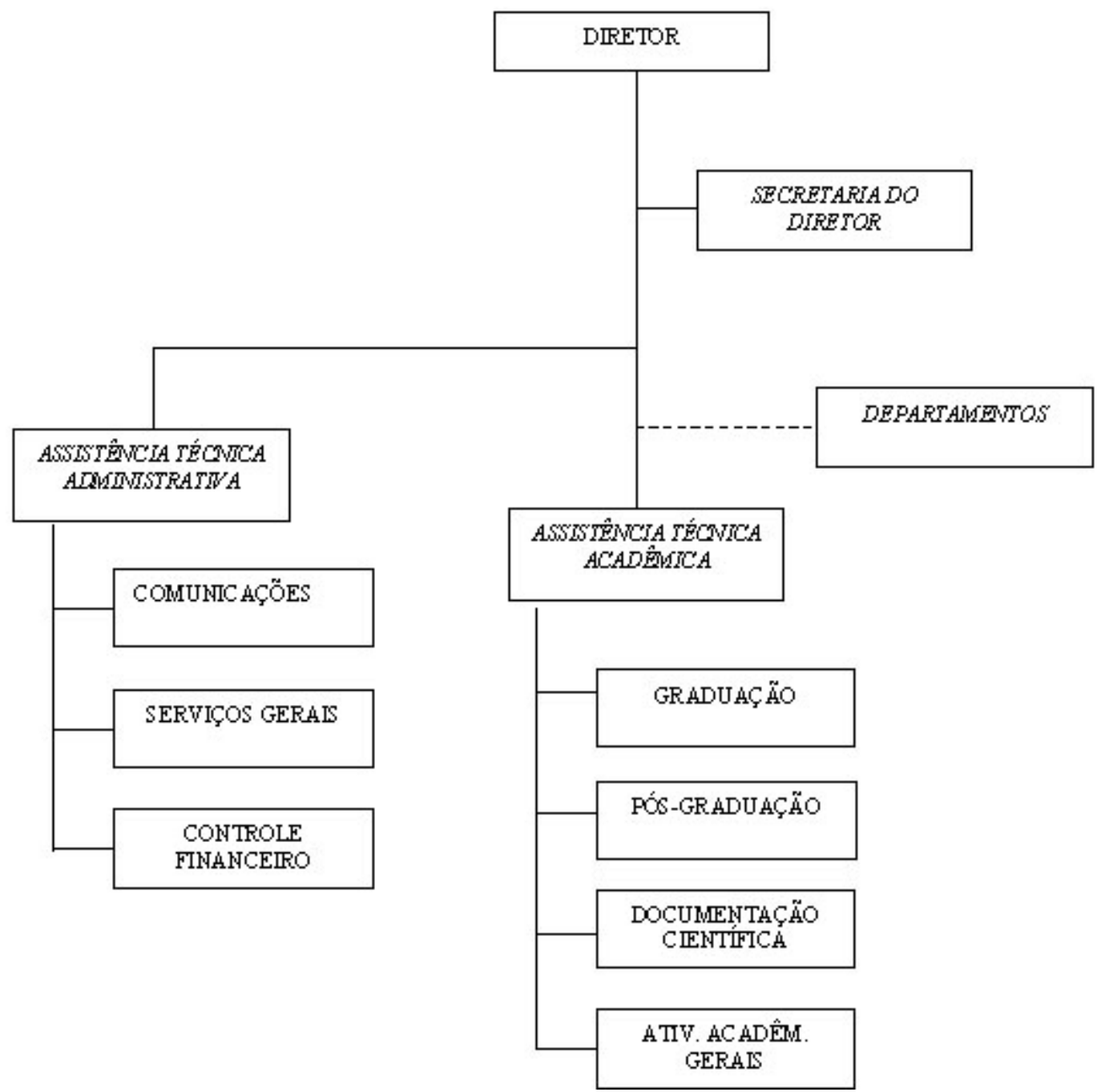

Figura 2 - Organograma Administrativo da FMRPUSP (1985-1996)

dados quantitativos da produção científica, o número de docentes, o número de teses defendidas e outros dados que refletem as atividades dos departamentos.

Em complementação ao orçamento, os recursos de fontes externas sempre desempenharam papel de grande relevância, destacando-se o apoio efetivo da FAPESP, da CAPES, do CNPq, da FINEP e outras às atividades científicas, formação e aperfeiçoamento dos pesquisadores. $\mathrm{O}$ apoio financeiro externo tem estimulado o desenvolvimento dos recursos humanos também na área gerencial, por implicar modificações na estrutura e nas atividades administrativas para viabilizar projetos. A aplicação de recursos fi- nanceiros externos requer diferentes formas de organização, para que se ofereçam respostas éticas aos conflitos legais.

A organização do trabalho da área financeira teve grande impacto com a informatização das atividades administrativas, especificamente pela implantação do Sistema Integrado de Administração Financeira - SIAF, em 1989 e, a seguir, no início da década de 90, pela introdução do Sistema Mercúrio. Este sistema, inicialmente moroso, passou por transformações que resultaram em melhorias comprovadas.

Destaca-se, no ano de 2002, a transferência da gerência financeira das bolsas de pós-graduação 


\section{ORGANOGRAMAADMINISTRATIVO DA FACULDADE DE MEDICINADE RIBEIRÃO PRETO - USP}

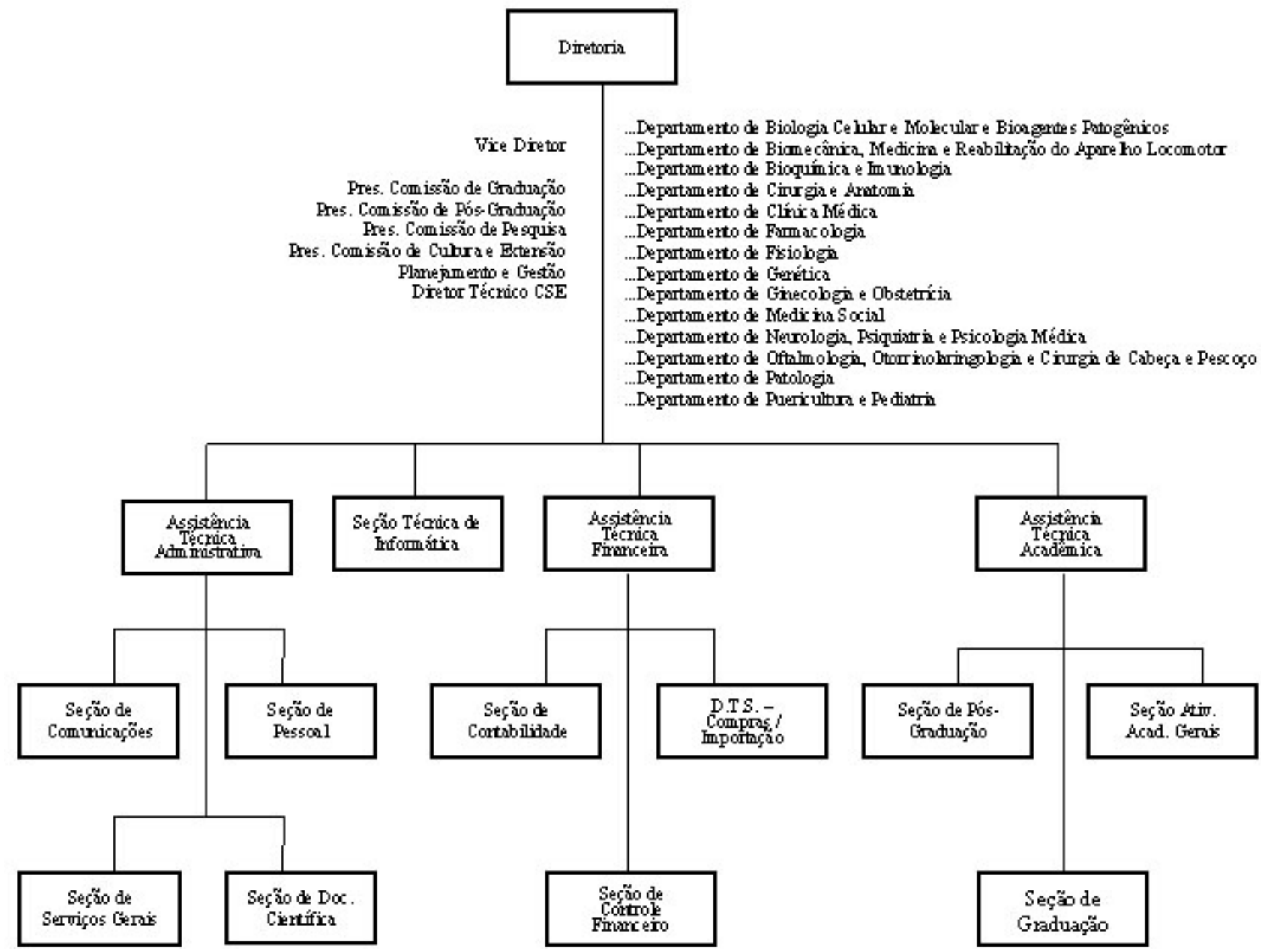

Figura 3 - Organograma Administrativo da FMRP-USP, a partir de 1996

CAPES para a ATF, liberando-se a Seção de PósGraduação para as suas atividades acadêmicas.

A área financeira passa por novas mudanças no âmbito do Programa de Gestão da Qualidade da FMRP-USP.

\section{A ASSESSORIA DE PLANEJAMENTO E GESTÃO}

Em 2001, após análise crítica das atividades de gestão da FMRP-USP, que mostrou a necessidade de ampliação do quadro administrativo da Diretoria, em razão do aumento do número de atividades e da complexidade decorrente das relações com outros órgãos governamentais e não governamentais, foi criada uma nova função, a de Assessoria de Planejamento e Ges- tão da FMRP-USP (APGe), em maio do mesmo ano. A criação da função não implicou contratação de mais um profissional. $\mathrm{O}$ exercício da função se deu por remanejamento interno da Assistente Técnica Financeira (ATF) para a nova função e o deslocamento de profissional da mesma área para exercer a função de ATF. A Assessoria de Planejamento e Gestão conta com o apoio direto de alunos estagiários da Universidade de São Paulo e da infra-estrutura de apoio existente nas áreas: Administrativa, Financeira e Acadêmica

Dentre as atividades de assessoria, previstas para a nova função destacam-se os seguintes programas: o Programa de Gestão da Qualidade da FMRP-USP; o Pólo Norte/Oeste Paulista de Formação Acadêmica e Capacitação de Recursos 
Humanos para a Saúde da Família, constituído por 13 Instituições que se articulam nas atividades do Programa de Saúde da Família do Sistema Único de Saúde (PSF-SUS); o programa que visa à aproximação dos Ex-Alunos, Graduados e Pós-graduados na FMRP-USP, e outros projetos que requerem assessoria transitória.

Acerca do Programa de Gestão da Qualidade da FMRP-USP, a Diretoria chamou a atenção, em várias oportunidades, para a necessidade de aprimoramento da gestão, e a importância de se buscar estratégias visando a maior articulação entre os profissionais, a começar pelos profissionais diretamente ligados à Diretoria $^{(4)}$. Foi realizado um trabalho com Assistentes da Diretoria, utilizando-se a técnica dos Grupos Operativos****** de Pichon Rivière. Além dessa experiência inédita na FMRP-USP, participaram, em outros Grupos Operativos, as Secretárias dos Departamentos, os Chefes de Seção e os Secretários executivos de outros serviços de apoio.

O objetivo mais importante dos Grupos Operativos, na FMRP-USP, é que mais e mais pessoas se tornem capazes de participar na construção de soluções para as dificuldades do cotidiano, como a agilização de processos e outros, além de aproximar os profissionais, melhorando o clima organizacional.

Face aos resultados alcançados, representados pelo aumento da produtividade dos Grupos Operativos e da melhoria do clima organizacional, a Diretoria pretende ampliar tal trabalho, oferecendo-o para maior número de profissionais, em 2003.

Finalmente, foi criado um grupo de Gestão da Qualidade da FMRP-USP, composto por docentes e outros profissionais da FMRP-USP, para tratar de assuntos administrativos priorizados pela Comunidade.

\section{REFERÊNCIAS BIBLIOGRÁFICAS}

1 - FURTADO HLAL. Relações do trabalho e desenvolvimento da gestão das atividades-meio. Dissertação de Mestrado, Faculdade de Economia e Administração da USP, São Paulo, 1997.

2 - SCHEIN EH. Organizational culture and leadership. Jossey-Bass, New York, 1992, p. 3-15.

3 - MOREIRA AC. O Jubileu da Faculdade de Medicina de Ribeirão Preto da Universidade de São Paulo e a Universidade em São Paulo. Sessão Solene do Conselho Universitário, em comemoração ao Cinqüentenário da Faculdade de Medicina de Ribeirão Preto. Ribeirão Preto, 17 de maio de 2002

4 - MOREIRA AC. Discurso de Posse à Diretoria da Faculdade de Medicina de Ribeirão Preto da Universidade de São Paulo. Ribeirão Preto, 02 de março de 2001.

\section{BIBLIOGRAFIAS CONSULTADAS}

UNIVERSIDADE DE SÃO PAULO. FACULDADE DE MEDICINADE RIBEIRÃO PRETO. Processo no. 82.1.40709.1.2. Estrutura Administrativa. Ribeirão Preto, 24/10/1986.

UNIVERSIDADE DE SÃO PAULO. FACULDADE DE MEDICINA DE RIBEIRÃO PRETO. Processos no. 89.1.1424.17.3. Estrutura Administrativa. Ribeirão Preto, 28/11/1989.

\footnotetext{
***** Em cada reunião, nos primeiros 30 min, era apresentado um tema de estudo pela facilitadora do Grupo Operativo. A seguir, iniciava-se a discussão, centrada no tema, favorecendo a interação e, muitas vezes, trazendo à tona o não explícito sobre o assunto, tais situações utilizadas com o objetivo de trazer esclarecimentos.
} 